\title{
Electro-Optical and Electrochemical Properties of a Conjugated Polymer Prepared by the Cyclopolymerization of Diethyl Dipropargylmalonate
}

\author{
Yeong-Soon Gal, ${ }^{1}$ Won-Chul Lee, ${ }^{1}$ Won Seok Lyoo, ${ }^{2}$ Sung-Ho Jin, ${ }^{3}$ Kwon Taek Lim, ${ }^{4}$ \\ Young-II Park, ${ }^{5}$ and Jong-Wook Park ${ }^{5}$ \\ ${ }^{1}$ Polymer Chemistry Laboratory, College of Engineering, Kyungil University, Kyungsan 712-701, South Korea \\ ${ }^{2}$ School of Textiles, Yeungnam University, Kyungsan 712-749, South Korea \\ ${ }^{3}$ Department of Chemistry and Center for Plastic Information System, Pusan National University, Pusan 609-735, South Korea \\ ${ }^{4}$ Division of Image and Information Engineering, Pukyong National University, Pusan 608-739, South Korea \\ ${ }^{5}$ Department of Chemistry, Center for Nanotechnology Research, The Catholic University, Bucheon 420-743, South Korea
}

Correspondence should be addressed to Yeong-Soon Gal, ysgal@kiu.ac.kr

Received 1 May 2008; Accepted 24 May 2008

Recommended by Mohamed Sabry Abdel-Mottaleb

The electro-optical and electrochemical properties of poly(diethyl dipropargylmalonate) were measured and discussed. Poly(diethyl dipropargylmalonate) prepared by (NBD) $\mathrm{PdCl}_{2}$ catalyst was used for study. The chemical structure of poly(diethyl dipropargylmalonate) was characterized by such instrumental methods as NMR $\left({ }^{1} \mathrm{H}-,{ }^{13} \mathrm{C}-\right)$, IR, and UV-visible spectroscopies to have the conjugated cyclopolymer backbone system. The microstructure analysis of polymer revealed that this polymer have the six-membered ring moieties majorly. The photoluminescence peak of polymer was observed at $543 \mathrm{~nm}$, which is corresponded to the photon energy of $2.51 \mathrm{eV}$. The cyclovoltamograms of the polymer exhibited the irreversible electrochemical behaviors between the doping and undoping peaks. It was found that the kinetics of the redox process of this conjugated cyclopolymer might be controlled by the diffusion-control process from the experiment of the oxidation current density of polymer versus the scan rate.

Copyright (c) 2008 Yeong-Soon Gal et al. This is an open access article distributed under the Creative Commons Attribution License, which permits unrestricted use, distribution, and reproduction in any medium, provided the original work is properly cited.

\section{INTRODUCTION}

Considerable progress has been made in the synthesis and optical characterization of conjugated organic polymers [13]. Polymers having a conjugated backbone are expected to show unique properties, such as electrical conductivity, paramagnetism, migration and transfer of energy, color, chemical reactivity, and complex formation ability [3-7]. Because of these properties, polyacetylene and its homologues have been promising materials for photovoltaics, displays, lasers, nonlinear optical materials, membranes for gas separation, and for liquid-mixture separation and chemical sensors $[4,5$, 8-12]. There are considerable interests in the development of electronic devices incorporating polymeric semiconductors owing to their superior properties, simplicity of fabrication, light weight, and potentially lower cost when compared to conventional inorganic semiconductors $[1-3,8,13]$.
Among the various types of reported polymer semiconductors, $\operatorname{poly}(p$-phenylenevinylenes $)$, polythiophenes, $\operatorname{poly}(9,9-$ dialkylfluorenes), and their derivatives are widely used in solar cell applications as $p$-type donor materials $[14,15]$.

The synthesis of conjugated polymer via the cyclopolymerization of dipropargyl monomers has been very interesting method for the introduction of conjugated system in the polymer main chain via an alternating intramolecularintermolecular chain propagation $[16,17]$. 1,6-Heptadiyne itself had been polymerized by various initiator systems to give poly(1,6-heptadiyne) with a polyene cyclic structure [17]. However, the resulting poly(1,6-heptadiyne) was insoluble in any organic solvent and unstable to air oxidation as like with that of polyacetylene [17]. Thus it was difficult for practical applications to optoelectronic devices as an active material. Introduction of substituents at 4-position of 1,6heptadiyne can enhance the processibility and stability of 
<smiles>CCOC(=O)C1(C(=O)OCC)CC(=CC(C)(C)C)C=C(C(C)(C)C)C1</smiles>

FIGURE 1: Chemical structure of poly(DEDPM).

the polyene systems, thus a variety of substituted poly $(1,6-$ heptadiyne)s were designed and synthesized [5, 7, 10, 18-20].

Diethyl dipropargylmalonate (DEDPM) is a wellknown cyclopolymerizable dipropargyl monomer since 1990 [21]. The polymerizations of DEDPM have been performed by $\mathrm{MoCl}_{5}, \mathrm{Mo}(\mathrm{CO})_{6}$, and $\mathrm{Cp}_{2} \mathrm{MoCl}_{2}$ catalyst, and high oxidation state alkylidene molybdenum complexes such as $\mathrm{Mo}\left(\mathrm{CHCMe}_{2} \mathrm{R}\right)\left(\mathrm{N}-2,6-\mathrm{C}_{6} \mathrm{H}_{3}-i-\mathrm{Pr}_{2}\right)\left(\mathrm{OCMe}_{2} \mathrm{CF}_{3}\right)_{2}$ and $\mathrm{Mo}\left(\mathrm{CHCMe}_{2} \mathrm{R}\right)\left(\mathrm{N}-2,6-\mathrm{C}_{6} \mathrm{H}_{3}-i-\mathrm{Pr}\right)_{2}(\mathrm{O}-\mathrm{t}-\mathrm{Bu})_{2}$ [21-24]. However, to date, the electro-optical and electrochemical properties of the resulting polymer from DEDPM were not systematically characterized.

Here, we prepared the conjugated cyclopolymer by the cyclopolymerization of DEDPM by (NBD) $\mathrm{PdCl}_{2}$. And we report the electro-optical and electrochemical properties of poly(DEDPM), a representative conjugated cyclopolymer (Figure 1).

\section{EXPERIMENTAL}

(Bicyclo[2.2.1]hepta-2,5-diene)dichloropalladium(II) (NBD) $\mathrm{PdCl}_{2}$ (Aldrich Chemicals) was used without further purification. Diethyl dipropargylmalonate (DEDPM) was prepared by the reaction of propargyl bromide and the sodium ethoxide solution of diethyl malonate according to the literature procedure [21]. The solvents were analytical grade materials. They were dried with an appropriate drying agent and fractionally distilled.

Poly(DEDPM) was prepared by the polymerization of DEDPM by using (NBD) $\mathrm{PdCl}_{2}$ catalyst. The polymerization procedure of DEDPM by (NBD) $\mathrm{PdCl}_{2}$ is as follows. In a $25 \mathrm{~mL}$ reactor equipped with rubber septum, $2.0 \mathrm{~g}(8.46 \mathrm{mmol})$ of DEDPM was added. Then $0.076 \mathrm{~g}$ of $(\mathrm{NBD}) \mathrm{PdCl}_{2}$ and $8 \mathrm{~mL}$ of DMF were added into the polymerization reactor (monomer to catalyst mole ratio: 30 , initial monomer concentration: $0.85 \mathrm{M}$ ). After 24 hours at $90^{\circ} \mathrm{C}$, the polymer solution diluted with $10 \mathrm{~mL}$ DMF was precipitated into a large excess of methanol. The precipitated polymer was filtered and dried in vacuum oven at $40^{\circ} \mathrm{C}$ for 24 hours. The polymer powder was obtained in $56 \%$ yield.

NMR $\left({ }^{1} \mathrm{H}\right.$ - and ${ }^{13} \mathrm{C}$ - $)$ spectra of polymer were recorded on a Varian $500 \mathrm{MHz}$ FT-NMR spectrometer (model: Unity INOVA) in $\mathrm{CDCl}_{3}$. FT-IR spectra were obtained with a Bruker EQUINOX 55 spectrometer using a $\mathrm{KBr}$ pellet. The optical absorption spectra were measured by an HP 8453 UV-visible Spectrophotometer. The photoluminescence spectra were obtained by Perkin Elmer luminescence spectrometer LS55 (Xenon flash tube) utilizing a lock-in amplifier system with a chopping frequency of
$150 \mathrm{~Hz}$. Electrochemical measurements were carried out with a Potentionstat/Galvanostat model 273 A (Princeton Applied Research). To examine electrochemical properties, the polymer solution was prepared and the electrochemical measurements were performed under $0.1 \mathrm{M}$ tetrabutylammonium tetrafluoroborate solution; containing acetonitrile. ITO, $\mathrm{Ag} / \mathrm{AgNO}_{3}$, and platinum wires were used as a working, reference, and counter electrode, respectively.

\section{RESULTS AND DISCUSSION}

We used the homogeneous (NBD) $\mathrm{PdCl}_{2}$ catalyst for the preparation of poly(DEDPM), which shows excellent solubility in the polymerization solvents and shows relatively stable. We had firstly used this catalyst for the cyclopolymerization of nonconjugated diyne monomers [25]. Unlike the polymerization behaviors of DEDPM by using Mo-based catalysts, which the polymerization proceeded rapidly in initial reaction stage $[21,23]$, the polymerization of DEDPM by (NBD) $\mathrm{PdCl}_{2}$ catalyst proceeded in mild homogeneous manner to give the moderate yield of polymer (56\%). And the number-average molecular weight and polydispersity of this polymer were 16,300 and 2.59 , respectively. The polymers were generally soluble in such organic solvents as chloroform, 1,4-dioxane, ethyl acetate, chlorobenzene, DMF, DMSO.

We characterized the chemical structure of poly(DEDPM) by using such instrumental methods as NMR $\left({ }^{1} \mathrm{H}-,{ }^{13} \mathrm{C}-\right)$, IR, and UV-visible spectroscopies. The FT-IR spectrum of polymer did not show the acetylenic $\mathrm{C} \equiv \mathrm{C}$ bond stretching and acetylenic $\equiv \mathrm{C}-\mathrm{H}$ bond stretching frequencies of DEDPM. The ${ }^{1} \mathrm{H}-\mathrm{NMR}$ spectrum of poly(DEDPM) prepared by (NBD) $\mathrm{PdCl}_{2}$ showed the broad vinyl protons of conjugated polymer backbone at the region of 5.4-7.2 ppm. The proton peaks at $2.5-3.6 \mathrm{ppm}$ and $3.9-4.1 \mathrm{ppm}$ are originated from the methylene protons adjacent to the conjugated carbons of polymer backbone and the methylene protons of ethyl side chains, respectively. The methyl proton peak of ethyl side chains was observed at 0.9-1.5 ppm.

The ${ }^{13} \mathrm{C}-\mathrm{NMR}$ spectrum of poly(DEDPM) did not show any acetylenic carbon peaks $(72.9,79.6 \mathrm{ppm})$ of DEDPM. Instead, the ${ }^{13} \mathrm{C}-\mathrm{NMR}$ spectrum of polymer showed new olefinic carbon peaks of the conjugated polymer backbone at the region of 118-142 ppm. The carbonyl carbon peak was also observed at $172 \mathrm{ppm}$. We obtained more detail information for the microstructures of poly(1,6-heptadiyne)-based conjugated cyclopolymers from the studies on the resonance for the quaternary carbon atoms [26]. It has been reported that the two clusters of resonances for the quaternary carbon atoms in poly(DEDPM) can be assigned to the quaternary carbons in five-membered rings (57-58 ppm) and six-membered rings (54-55 ppm), respectively. Figure 2 shows the ${ }^{13} \mathrm{C}-\mathrm{NMR}$ spectrum of poly(DEDPM) in the region of methine carbon peak. The peaks at 56-59 ppm were only observed, which means that the present poly(DEDPM) was majorly composed of six-membered ring moieties.

The electro-optical properties of poly(DEDPM) were measured and discussed. Figure 3 shows the UV-visible and photoluminescence (PL) spectra of poly(DEDPM) solution 


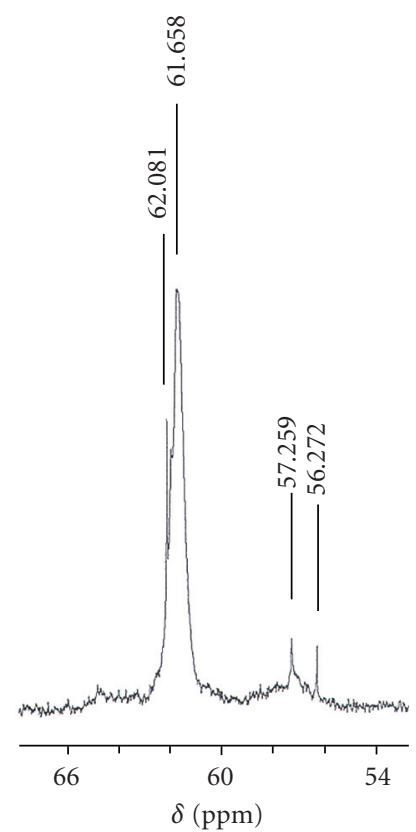

FIGURE 2: ${ }^{13} \mathrm{C}$-NMR spectrum of poly(DEDPM) in the region of methine carbon.

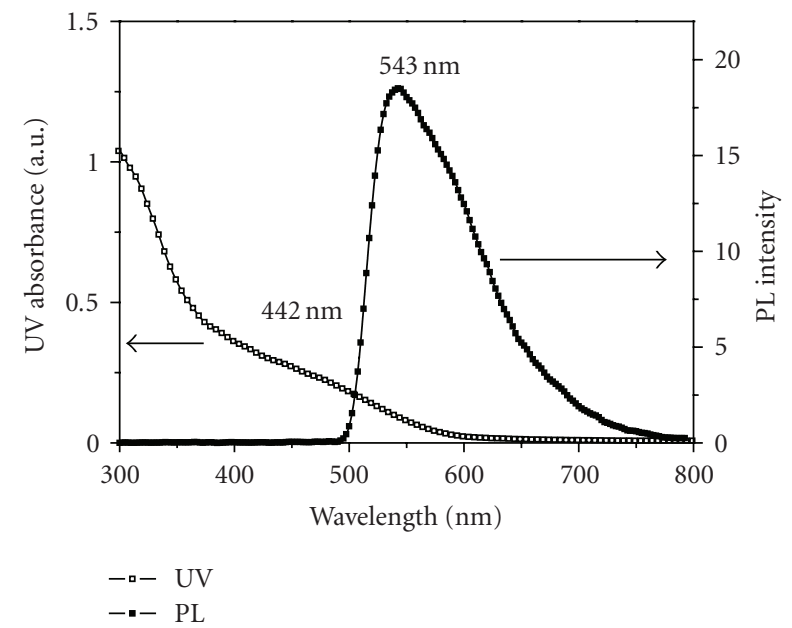

FIgURE 3: Optical absorption and photoluminescence spectra of poly(DEDPM) solution.

(0.025 wt.\%, DMF). In our previous paper [27], we had reported the UV-visible and PL spectra of poly(2-ethynyl$\mathrm{N}$-propagylpyridinium bromide) which has similar polymer backbone, conjugated polyene, and tied six-membered ring, it showed $460 \mathrm{~nm}$ of UV-visible maximum value and $510 \mathrm{~nm}$ of PL maximum value at excitation wavelength of $460 \mathrm{~nm}$. Poly(DEDPM) also exhibited characteristic UV-visible absorption band at $442 \mathrm{~nm}$ and green PL spectrum at $543 \mathrm{~nm}$ corresponding to the photon energy of $2.28 \mathrm{eV}$. The reason why two polymers showed different maximum values is that poly(DEDPM) does not have an extra conjugation moiety attached to conjugated polyene which is a polymer backbone.

In order to characterize the electrochemical kinetic behaviors and an electrochemically stable window, the cyclic

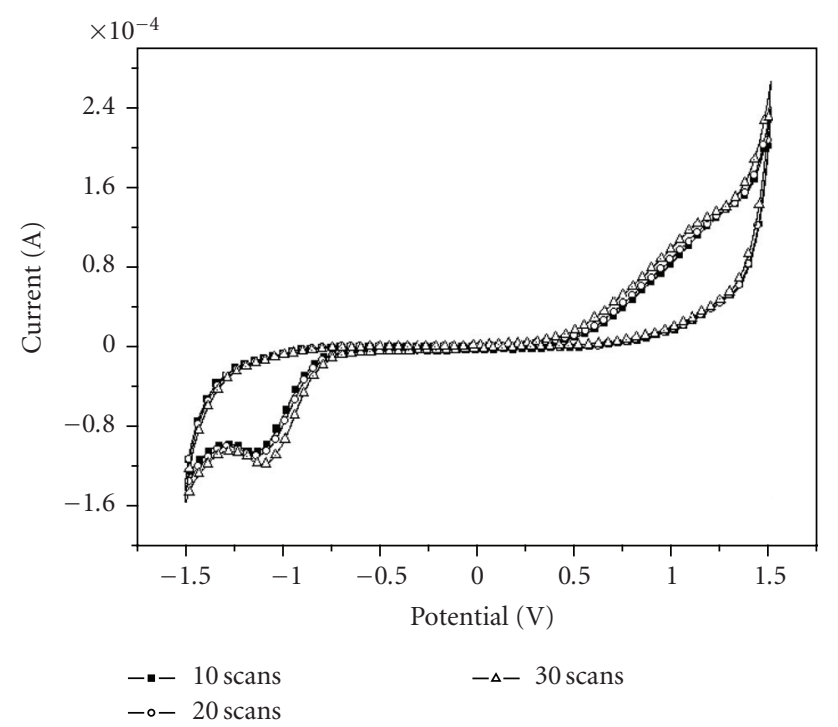

(a)

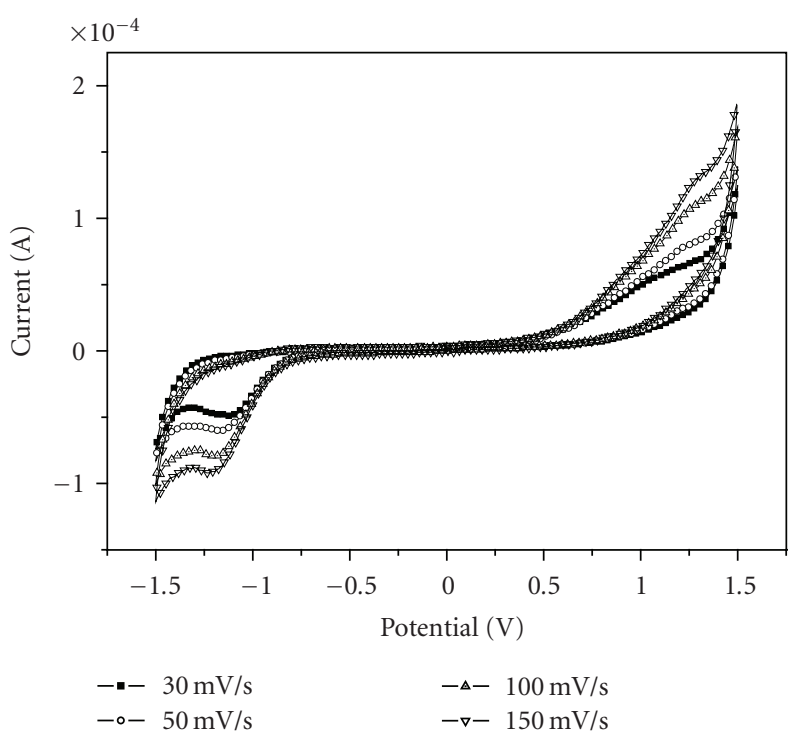

(b)

FIGURE 4: Cyclic voltammograms of poly(DEDPM) [0.1M ( $n$ $\mathrm{Bu})_{4} \mathrm{NBF}_{4} / \mathrm{DMF}$ ] (a) consecutive 30 scans under $100 \mathrm{mV} / \mathrm{s}$ and (b) $30 \mathrm{mV} / \mathrm{sec} \sim 120 \mathrm{mV} / \mathrm{sec}$ with various scan rates.

voltammograms (CVs) of poly(DEDPM) including a consecutive scan and various scan rates $(30 \mathrm{mV} / \mathrm{s} \sim 150 \mathrm{mV} / \mathrm{s})$ were recorded as shown in Figure 4(b). Typical CVs obtained at the scan rate of $100 \mathrm{mV} / \mathrm{s}$ for poly(DEDPM) solution are presented in Figure 4(a). We have observed that the shape of CVs is almost unchanged, concluding that poly(DEDPM) is fairly stable without any severe degradation up to 30 cycles of the consecutive scan. In Figure 4(b), as the speed of scan rate was increased, the peak potentials were gradually shifted to higher potentials and the current values were increased. Finally, the oxidation of poly(DEDPM) was occurred at $0.46 \mathrm{~V}$ (versus $\mathrm{Ag} / \mathrm{AgNO}_{3}$ ), where the vinylene group of conjugated polymer backbone might be oxidized in the scan. Poly(DEDPM) also shows the irreversible reduction at $-0.83 \mathrm{~V}$. The redox current value was gradually increased 


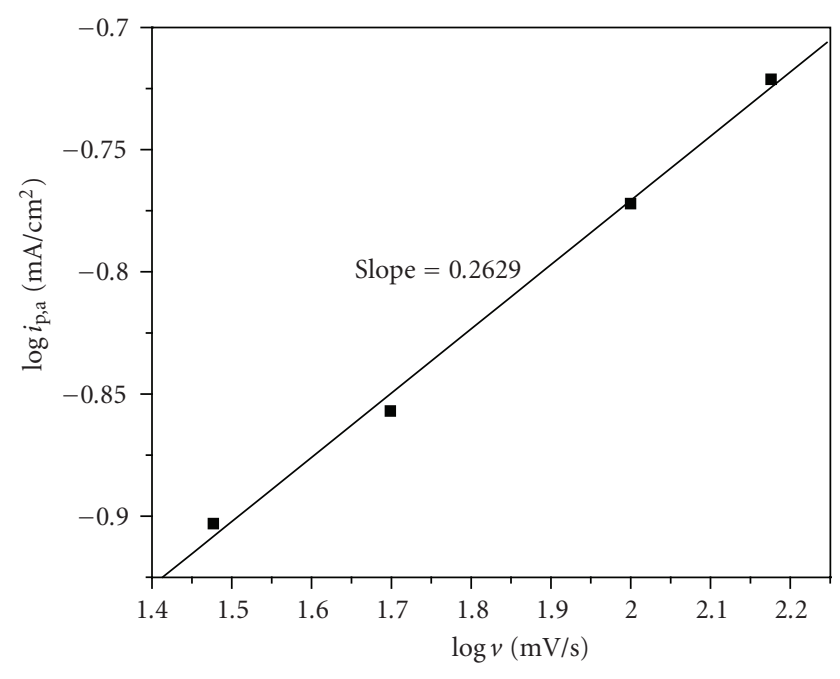

Figure 5: Plot of $\log i_{\mathrm{p}, \mathrm{a}}$ versus $\log v$ for poly(DEDPM).

as the scan rate was increased. This result suggests that the electrochemical process of poly(DEDPM) is reproducible in the potential range of $-1.5 \sim+1.5 \mathrm{~V}$ versus $\mathrm{Ag} / \mathrm{AgNO}_{3}$.

It has been reported that the relationship between the redox peak current and the scan rate can be expressed as a power-law type as follows [28-30]:

$$
\begin{aligned}
i_{\mathrm{p}, \mathrm{a}} & =k v^{x}, \\
\log i_{\mathrm{p}, \mathrm{a}} & =\log k+x \log v,
\end{aligned}
$$

where $i_{\mathrm{p}, \mathrm{a}}=$ oxidation peak current density, $v=$ scan rate, $k=$ proportional constant, and $x=$ exponent of scan rate.

Considering that electrode kinetics satisfies (1), the electrochemical redox reaction is controlled by either the electron transfer process, where $x=1$, or the reactant diffusion process, where $x=0.5$. The relationship plot of the oxidation current density $\left(\log i_{\mathrm{p}, \mathrm{a}}\right)$ as a function of the scan rate $(\log v)$ is shown in Figure 5. The oxidation current of poly(DEDPM) versus the scan rate is approximately linear relationship in the range of $30 \mathrm{mV} / \mathrm{sec} \sim 150 \mathrm{mV} / \mathrm{sec}$ and the exponent of scan rate $x$ value is found to be 0.262 . It is explained by that the kinetics of the redox process may not reach to the diffusion-control process and not be so fast electro-active although it has very stable durability for electrochemical process.

\section{CONCLUSIONS}

The electro-optical and electrochemical properties of a typical conjugated cyclopolymer, poly(DEDPM), were measured and discussed. Poly(DEDPM) was prepared by (NBD) $\mathrm{PdCl}_{2}$ catalyst in $56 \%$ yield. The chemical structure of poly(DEDPM) was characterized to have the conjugated polymer system with the designed repeating unit. The present poly(DEDPM) was found to be composed of sixmembered ring moieties majorly from the analysis of methine carbon peaks in ${ }^{13} \mathrm{C}-\mathrm{NMR}$ spectrum. The photoluminescence (PL) spectra of poly(DEDPM) showed that the photoluminescence peak is located at $543 \mathrm{~nm}$ corresponding to the photon energy of $2.51 \mathrm{eV}$. The CVs of the polymer exhibited the irreversible electrochemical behaviors between the doping and undoping peaks. It was found that the kinetics of the redox process of poly(DEDPM) might be controlled by the diffusion-control process from the experiment of the oxidation current density of poly(DEDPM) versus the scan rate.

\section{ACKNOWLEDGMENT}

This work was supported by Grant no. RTI04-01-04 from the Regional Technology Innovation Program of the Ministry of Knowledge Economy (MKE), South Korea.

\section{REFERENCES}

[1] V. Coropceanu, J. Cornil, D. A. da Silva Filho, Y. Olivier, R. Silbey, and J.-L. Brédas, "Charge transport in organic semiconductors," Chemical Reviews, vol. 107, no. 4, pp. 926952, 2007.

[2] Y. Shirota and H. Kageyama, "Charge carrier transporting molecular materials and their applications in devices," Chemical Reviews, vol. 107, no. 4, pp. 953-1010, 2007.

[3] E. Menard, M. A. Meitl, Y. Sun, et al., "Micro- and nanopatterning techniques for organic electronic and optoelectronic systems," Chemical Reviews, vol. 107, no. 4, pp. 1117-1160, 2007.

[4] K. Tsuchihara, T. Masuda, and T. Higashimura, "Tractable silicon-containing poly(diphenylacetylenes): their synthesis and high gas permeability," Journal of the American Chemical Society, vol. 113, no. 22, pp. 8548-8549, 1991.

[5] S.-K. Choi, Y.-S. Gal, S.-H. Jin, and H.-K. Kim, "Poly(1,6heptadiyne)-based materials by metathesis polymerization," Chemical Reviews, vol. 100, no. 4, pp. 1645-1681, 2000.

[6] S.-H. Jin, M.-Y. Kim, J. Y. Kim, K. Lee, and Y.-S. Gal, "Highefficiency poly ( $p$-phenylenevinylene)-based copolymers containing an oxadiazole pendant group for light-emitting diodes," Journal of the American Chemical Society, vol. 126, no. 8, pp. 2474-2480, 2004.

[7] Y.-S. Gal, S.-H. Jin, H.-S. Lee, and S. Y. Kim, "Synthesis and properties of conjugated cyclopolymers bearing fluorene derivatives," Macromolecular Research, vol. 13, no. 6, pp. 491498, 2005.

[8] J. W. Y. Lam and B. Z. Tang, "Functional polyacetylenes," Accounts of Chemical Research, vol. 38, no. 9, pp. 745-754, 2005.

[9] T. Masuda, "Substituted polyacetylenes," Journal of Polymer Science, Part A, vol. 45, no. 1, pp. 165-180, 2007.

[10] Y.-S. Gal, W.-C. Lee, S.-H. Jin, et al., "Cyclopolymerization of $\alpha$-methylbenzyl dipropargylamine by transition metal catalysts," Macromolecular Research, vol. 15, no. 3, pp. 267271, 2007.

[11] Y.-S. Gal, S.-H. Jin, and J.-W. Park, "Synthesis and properties of an ionic polyacetylene with aromatic heterocycles," Journal of Polymer Science, Part A, vol. 45, no. 23, pp. 5679-5685, 2007.

[12] Y.-S. Gal, W.-C. Lee, S.-H. Jin, et al., "Synthesis and electrochemical properties of poly[N-(6-azidohexyl)-2ethynylpyridinium tetraphenylborate]," Molecular Crystals and Liquid Crystals, vol. 472, no. 1, pp. 271-278, 2007.

[13] K. Walzer, B. Männig, M. Pfeiffer, and K. Leo, "Highly efficient organic devices based on electrically doped transport layers," Chemical Reviews, vol. 107, no. 4, pp. 1233-1271, 2007. 
[14] S. Günes, H. Neugebauer, and N. S. Sariciftci, "Conjugated polymer-based organic solar cells," Chemical Reviews, vol. 107, no. 4, pp. 1324-1338, 2007.

[15] Md. A. Karim, Y.-R. Cho, J. S. Park, et al., "Novel fluorenebased functional 'click polymers' for quasi-solid-state dyesensitized solar cells," Chemical Communications, no. 16, pp. 1929-1931, 2008.

[16] G. B. Butler, "Cyclopolymerization and cyclocopolymerization," Accounts of Chemical Research, vol. 15, no. 11, pp. 370378, 1982.

[17] H. W. Gibson, F. C. Bailey, A. J. Epstein, et al., "Poly(1,6heptadiyne), a free-standing polymer film dopable to high electrical conductivity," Journal of the American Chemical Society, vol. 105, no. 13, pp. 4417-4431, 1983.

[18] Y.-S. Gal and S. K. Choi, "Cyclopolymerization of dipropargyl ether by transition metal catalysts," Polymer (Korea), vol. 11, no. 6, pp. 563-571, 1987.

[19] B. V. K. Naidu, B.-H. Oh, D.-H. Nam, et al., "Transition-metalcatalyzed conjugated polymers of 1,6-heptadiyne derivatives in supercritical carbon dioxide," Journal of Polymer Science, Part A, vol. 44, no. 4, pp. 1555-1560, 2006.

[20] C. Czekelius, J. Hafer, Z. J. Tonzetich, R. R. Schrock, R. L. Christensen, and P. Müller, "Synthesis of oligoenes that contain up to 15 double bonds from 1,6-heptadiynes," Journal of the American Chemical Society, vol. 128, no. 51, pp. 16664$16675,2006$.

[21] M.-S. Ryoo, W.-C. Lee, and S.-K. Choi, "Cyclopolymerization of diethyl dipropargylmalonate by transition-metal catalysts," Macromolecules, vol. 23, no. 12, pp. 3029-3031, 1990.

[22] S.-J. Jeon, D.-J. Cho, S.-C. Shim, T.-J. Kim, and Y.-S. Gal, " $\mathrm{Mo}(\mathrm{CO})_{6}$-catalyzed cyclopolymerization of diethyl dipropargylmalonate to give a polyene containing only five-membered rings," Journal of Polymer Science, Part A, vol. 37, no. 7, pp. 877-880, 1999.

[23] Y.-S. Gal, S.-H. Jin, S.-H. Kim, et al., "Cyclopolymerization of dipropargyl derivatives by $\mathrm{Cp}_{2} \mathrm{MoCl}_{2}-\mathrm{EtAlCl}_{2}$ catalyst system," Journal of Macromolecular Science, Part A, vol. 39, no. 3, pp. 237-249, 2002.

[24] J. O. Krause, D. Wang, U. Anders, et al., "Stereoselective cyclopolymerization of diynes: smart materials for electronics and sensors," Macromolecular Symposia, vol. 217, no. 1, pp. 179-190, 2004.

[25] Y.-S. Gal, S.-H. Jin, A. R. Hyun, et al., "Electro-optical and electrochemical properties of a conjugated cyclopolymer: poly(9,9-dipropargylfluorene)," Journal of Industrial and Engineering Chemistry. In press.

[26] H. H. Fox, M. O. Wolf, R. O’Dell, B. L. Lin, R. R. Schrock, and M. S. Wrighton, "Living cyclopolymerization of 1,6heptadiyne derivatives using well-defined alkylidene complexes: polymerization mechanism, polymer structure, and polymer properties," Journal of the American Chemical Society, vol. 116, no. 7, pp. 2827-2843, 1994.

[27] Y.-S. Gal, T. L. Gui, S.-H. Jin, et al., "Electro-optical properties of water-soluble conjugated polymer," Synthetic Metals, vol. 135-136, pp. 353-354, 2003.

[28] J. M. Ko, H. W. Rhee, S.-M. Park, and C. Y. Kim, "Morphology and electrochemical properties of polypyrrole films prepared in aqueous and nonaqueous solvents," Journal of the Electrochemical Society, vol. 137, no. 3, pp. 905-909, 1990.

[29] A. J. Bard and L. R. Faulker, Electrochemical Methods, chapters 3, 6 and 10, John Wiley \& Sons, New York, NY, USA, 1980.

[30] Y. E. Kim, Y. S. Kwon, K. S. Lee, J.-W. Park, H. J. Seo, and T. W. Kim, "Synthesis and electrochemical properties of
N-substituted bicarbazyl derivatives," Molecular Crystals and Liquid Crystals, vol. 424, pp. 153-158, 2004. 


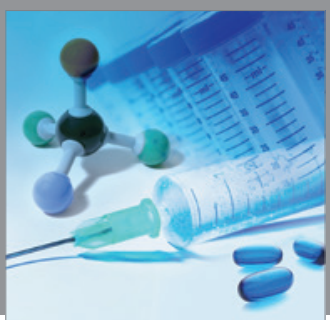

International Journal of

Medicinal Chemistry

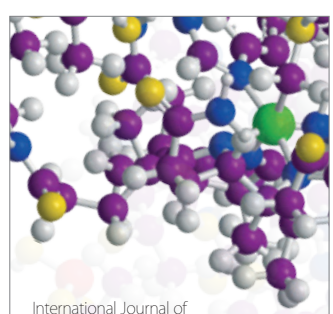

Carbohydrate Chemistry

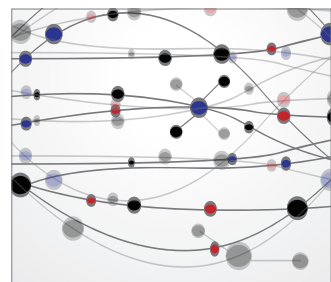

The Scientific World Journal
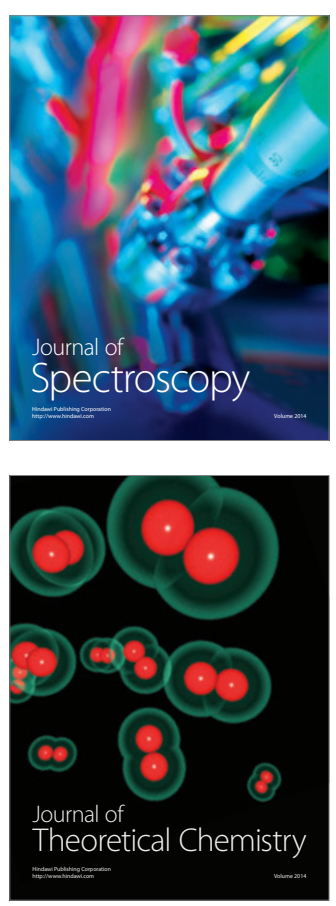
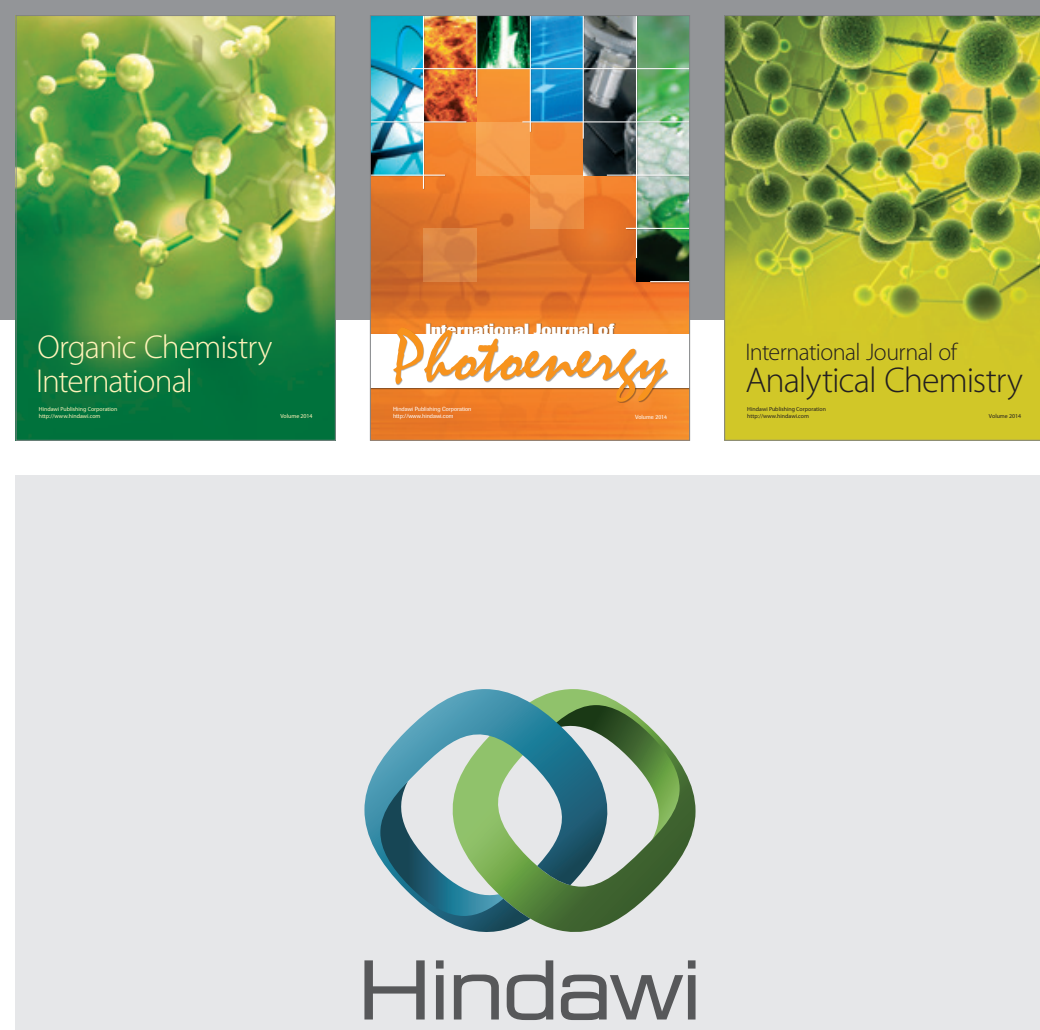

Submit your manuscripts at

http://www.hindawi.com
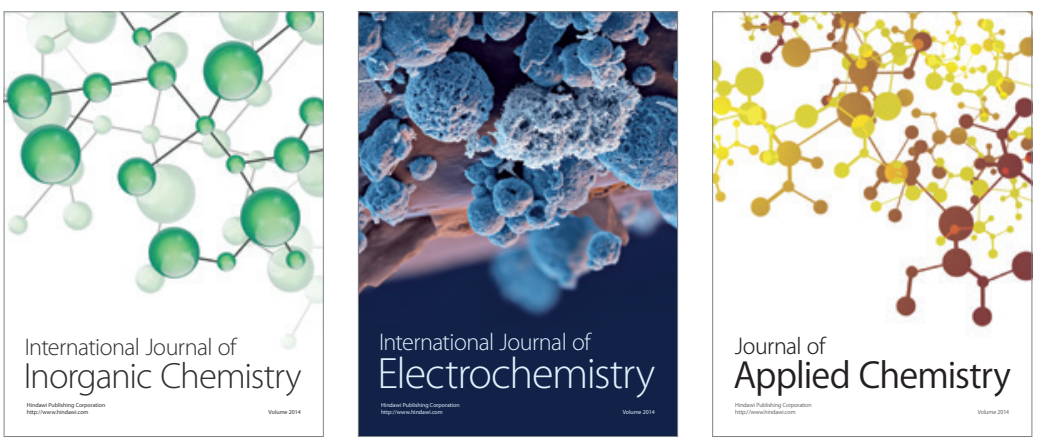

Journal of

Applied Chemistry
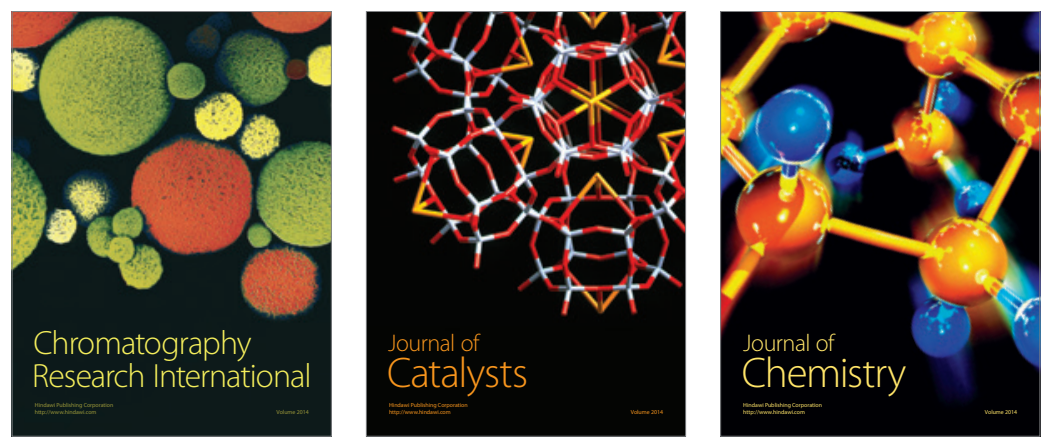
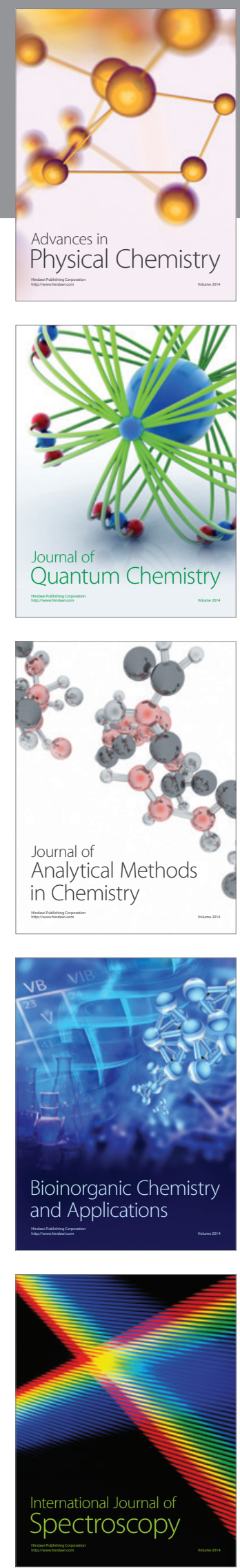